\title{
Comparing the Efficacy of Postoperative Diclofenac Suppository with Intramuscular Diclofenac in Children under going Inguinal Hernia Surgery
}

\author{
Ayesha Yaqeen ${ }^{1}$, Hafiza Sidra ${ }^{2}$, Maria Saeed ${ }^{3}$ \\ 1,3. House Officer, Bahawal Victoria Hospital, Bahawalpur. \\ 2.House Officer, Nishtar Hospital, Multan. \\ Corresponding Author: ayeshayaqeen@gmail.com
}

\begin{abstract}
:
Objective: To compare the analgesic effect of postoperative Diclofenac suppository with intramuscular Diclofenac in children undergoing inguinal hernia surgery. Methodology: This study was held in Paeds Surgery Department, Nishtar Hospital Multan, Bahawal Victoria hospital Bahawalpur. from August 2018 to March 2019. Total no. of 160 patients were divided into two groups, one receiving diclofenac suppository group DS and the other which was group DI received intramuscular diclofenac injection. Numerical variables like age and weight were analyzed statistically by taking their mean and standard deviation while the outcome variable i.e. severity of pain was assessed through facial expressions as no pain, mild, moderate and severe pain in frequency percentage at 0, 2 and 4 hours interval. Results: Total 160 patients were divided into 2 groups equally, 80 in each (DS \& DI). There was no significant difference in the efficacy of diclofenac suppository and diclofenac intramuscular when calculated at 0,2 and 4 hours interval. When Chi-Square was applied to determine the association, it was observed that pain severity was significantly associated with age. But the association of pain severity with weight and with time intervals in two groups was not statistically significant. Conclusion: From this study we conclude that there is no significant difference between the postoperative analgesic effect of either suppository or intramuscular diclofenac but suppository route has an advantage over intramuscular in that it is easier and safer, less prone to injury, easy to administer and has longer duration of action, especially preferable in pediatric patients.
\end{abstract}

Keywords: Children, diclofenac Sodium, inguinal Hernia, intramuscular, suppository

DOI: $10.7176 / \mathrm{JMPB} / 65-05$

Publication date: April $30^{\text {th }} 2020$

\section{Introduction:}

The incidence of inguinal hernia is almost 80,000 children in world. It was found that the cumulative incidence of inguinal hernia from birth to 15 years of age was $0.74 \%$ in females and $6.62 \%$ in males $\{1,2\}$. While in the adult population almost all cases of sliding hernias are seen in men $\{3\}$.

The processus vaginalis is an embryonic developmental out pouching of peritoneum attached to the testicle. When obliteration of the processus vaginalis fails to occur, it results into inguinal hernia. Inguinal hernia is an indication of elective herniotomy(in children) herniorraphy(in adults), which prevents incarceration and subsequent strangulation. Multiple factors contributing to chronic pain include scrotal hernia, hernia repair or emergency recurrent hernia repair. Postoperative pain may be less with laparoscopic procedures as compared to open procedures $\{4\}$. Pain caused by tension or compression may slowly diminish with time as a consequence of tissue reorganization $\{5\}$.

The quality and duration of analgesia provided by morphine remain without comparison $\{6\}$. But due to the complications of opioids, in recent times physicians have been paying attention on NSAIDs for pain control $\{7\}$. NSAID, Diclofenac which reduces inflammation and relieves pain. It is used to treat dental pain, muscle aches and athletic injuries. It is frequently used to treat the swelling, stiffness and pain related with arthritis $\{8\}$.

Perioperative analgesia in pediatrics herniotomies requires effective, safe and less invasive strategies. Local infiltration with Bupivacaine, caudal Bupivacaine and rectal Diclofenac are widely used to alleviate the pain. Hernia repair is an outpatient procedure. Patients are usually healthy and full-term child or infant. Diclofenac restrain prostaglandin synthesis by lessening cyclo-oxygenase activity, which sequentially, reduces formation of prostaglandin precursors. Diclofenac suppository with local infiltration is an effective and less invasive alternative to caudal Bupivacaine for postoperative pain relief in pediatric hernia repair. 
Different studies have been performed about the efficacy of analgesics for postoperative pain of inguinal hernia but there is lack of studies for effect of route of administration of diclofenac. This study is planned to compare intramuscular and suppository route of administration of diclofenac to see which of these is more effective.

\section{Patients and Methods:}

Children who presented for inguinal hernia repair were included in the study. For our study sample size was calculated using reference from a previous study by Saghar Samimi Sede et al. ${ }^{9}$ For which confidence interval was taken as $95 \%$, power of study $80, \mathrm{Mean} \pm \mathrm{SD}$ of duration of analgesia for control and study group $13.9 \pm 2.7$ and $16.8 \pm 2.8$ respectively. ${ }^{9}$

Authorization for the study protocol was obtained from the Hospital Ethics Committee and informed written permission was obtained from the parents of all children. This study is randomized control trail.Non probability sampling technique was used . patients were randomly divided in two groups by lottery method. Children from age 5-15 years, who were operated for inguinal hernia were included in the study. Patients with history of asthma, known allergy or contraindication for study drug, kidney or hepatic dysfunction, duration of surgery more than two hours or refuses to give informed consent were excluded from study. Study was performed in Pediatrics Surgery Department, Nishtar Hospital Multan, Bahawal Victoria hospital Bahawalpur. from August 2018 to March 2019. Patients were divided into two groups, one receiving diclofenac suppository (DS group) and the other group getting intramuscular diclofenac injection (DI group).

Standard patient monitoring involved measurement of blood pressure, pulse oximetry, electrocardiograph, inhalation agents and capnography. General anesthesia was administered by inhalation of sevoflurane in oxygen or intravenously with $2.5-3.5 \mathrm{mg} / \mathrm{kg}$ propofol. A laryngeal mask airway was inserted after induction of anesthesia. All patients were administered 50 micro gram $/ \mathrm{kg}$ midazolam immediately after induction of anesthesia and $60 \%$ nitrous oxide, $40 \%$ oxygen, and sevoflurane during their operation. The sevoflurane concentration $(2.0 \%)$ was regulated to achieve optimum intraoperative hemodynamic measurements. Intravenous fluids were administered in the operating room following standard guidelines (Ringer's lactate solution at maintenance rates).

Postoperatively group DS received diclofenac suppository $2.5 \mathrm{mg} / \mathrm{kg}$ and group DI received intramuscular diclofenac $2 \mathrm{mg} / \mathrm{kg}$. Patients were evaluated for severity of pain by a single autonomous observer 0,2 and 4 hours after the return to the ward. Pain was evaluated using visual analogue score, in which no pain was labeled when VAS 0. mild pain when VAS 1-4, moderate pain when VAS 5-8 and severe pain when patient had VAS 910. Visual analogue scoring scale is a linear scale from 0 to 10 number. which shows intensity of pain increase as number increase.

For continuous variables, mean and SD were calculated. While categorical variables were analyzed as number and percentage. Post stratification Chi square test was applied to check effect modification and $\mathrm{T}$ test was applied to check the difference among both groups and to calculate the $\mathrm{p}$ value .

\section{Results:}

A total no. of $160(100 \%)$ patients were included in study and all were males. The mean age and weight of the patients was $10.94 \pm 2.55$ years and $31.04 \pm 10.45 \mathrm{~kg}$ respectively (Table 1 ).

Patients were divided into 2 groups equally, 80 in each, i.e. Group (DS) and group (DI). The mean age and weight of the patients in group (DS) was $10.85 \pm 2.72$ years and $31.82 \pm 11.76 \mathrm{~kg}$ respectively. While the mean age and weight of the patients in group (DI) was $11.03 \pm 2.37$ years and $30.12 \pm 9.27 \mathrm{~kg}$ respectively. No significant difference was found between age $(\mathrm{t}=-0.551, \mathrm{P}$-value $=0.583)$ and weight $(\mathrm{t}=-0.529, \mathrm{P}$ value $=0.598)$ in groups, after applying the independent samples t test (Table-2).

The main outcome variable of this study was Pain Severity. The mean severity of pain was $1.89 \pm 1.03$ and $2.00 \pm 1.006$ for the groups (DS) and (DI) respectively. It was observed that, in group (DS), at 0 hour, ( $\mathrm{n}=23$ ) $29.6 \%$ patients had no pain, $40.7 \%(n=33)$ had mild pain, $18.5 \%(n=15)$ had moderate pain and $11.1 \%(n=9)$ had severe pain. At 2 hours, 50\% $(\mathrm{n}=40)$ patients had no pain, $23.1 \%(\mathrm{n}=18)$ had mild pain, $11.5 \%(\mathrm{n}=10) \mathrm{had}$ moderate pain and $15.4 \%(\mathrm{n}=12)$ had severe pain. At 4 hours, $63 \%(\mathrm{n}=50)$ patients had no pain, $18.5 \%(\mathrm{n}=15)$ mild pain, $11.1 \%(n=9)$ moderate pain and 7.4\% $(n=6)$ had severe pain (Table 4$)$. It was also noted that, in group (DI), at 0 hour, 23.1\% $(\mathrm{n}=18)$ patients had no pain, 46.2\% $(\mathrm{n}=37)$ had mild pain, $26.9 \%(\mathrm{n}=21)$ had moderate pain and 3.8\% $(n=4)$ had severe pain. At 2 hours, $42.3 \%(n=34)$ patients had no pain, $26.9 \%(n=21)$ had mild pain, $11.5 \%(\mathrm{n}=9)$ had moderate pain and $19.2 \%(\mathrm{n}=16)$ had severe pain. At 4 hours, $53.3 \%(\mathrm{n}=43)$ patients had no pain, $17.9 \%(n=14)$ mild pain, $21.4 \%(n=17)$ moderate pain and $7.1 \%(n=6)$ had severe pain (Table 5). To 
check the equality of the means, severity of pain, in groups, independent samples t-test was applied. No significant difference was found between mean severities of pain in groups $(\mathrm{t}=-0.698, \mathrm{p}=0.486)$. (Table 2$)$.

When patients were stratified into different age and weight groups, it was noted that most of patients i.e. $55.6 \%(n=89)$ were aged from 11 to 15 years while $44.4 \%(n=71)$ patients were aged from 5 to 10 years. Majority of the patients i.e. $62.5 \%(\mathrm{n}=100)$ had weight $26-48 \mathrm{~kg}$ and only $37.5 \%(\mathrm{n}=60)$ had $12-25 \mathrm{~kg}$ of weight (Table 1).

Chi-Square was applied to check the association; it was observed that severity of pain was notably associated with stratified age with p-value 0.010 . But it was not considerably associated with stratified weight with p-value 0.174 (Table 3 ).

Table- 1

Demographic Variables:

$(\mathbf{n}=\mathbf{1 6 0})$

\begin{tabular}{|l|c|c|}
\hline \multicolumn{1}{|c|}{ Characteristics } & Frequency & Percentage (\%) \\
\hline Stratified Age & 71 & 44.4 \\
\hline 5-10 years & 89 & 55.6 \\
\hline $11-15$ years & 160 & 100.0 \\
\hline Total & 60 & 37.5 \\
\hline Stratified Weight & 100 & 62.5 \\
\hline $12-25 \mathrm{~kg}$ & 160 & 100.0 \\
\hline 26-48 & \multicolumn{2}{c|}{} \\
\hline Total & Mean & S.D \\
\hline Descriptive Statistics & 10.94 & 2.55 \\
\hline \multicolumn{2}{|c|}{} & 31.04 \\
\hline Age (years) & & 10.45 \\
\hline Weight kg &
\end{tabular}

Table 2

Difference of outcome and demographic variables.

\begin{tabular}{|c|c|c|c|}
\hline Variables & DS Group & DI Group & Test of Sig. \\
\hline Age & $7.61 \pm 1.60$ years & $7.75 \pm 1.55$ years & $\mathrm{t}=-0.551, \mathrm{p}=0.583$ \\
\hline Weight & $15.88 \pm 3.08 \mathrm{~kg}$ & $16.15 \pm 3.19 \mathrm{~kg}$ & $\mathrm{t}=-0.528, \mathrm{p}=0.598$ \\
\hline Pain Severity & $1.89 \pm 1.03$ & $2.00 \pm 1.006$ & $\mathrm{t}=-0.698, \mathrm{p}=0.486$ \\
\hline
\end{tabular}

Table No. 3

Association of Pain Severity with Effect Modifiers $(\mathrm{n}=\mathbf{1 6 0})$

\begin{tabular}{|c|c|c|c|c|c|c|c|}
\hline \multicolumn{2}{|c|}{ Effect Modifiers } & \multicolumn{4}{|c|}{ Pain Severity } & \multirow[t]{2}{*}{ Total } & \multirow[t]{2}{*}{ P-value } \\
\hline & & No & Mild & Moderate & Severe & & \\
\hline \multirow{3}{*}{ Stratified Age } & $5-10$ years & & & & & & \multirow{4}{*}{0.010} \\
\hline & & 38 & 11 & 14 & 8 & 71 & \\
\hline & $11-15$ years & 32 & 35 & 13 & 9 & 89 & \\
\hline \multicolumn{2}{|c|}{ Total } & 70 & 46 & 27 & 17 & 160 & \\
\hline \multirow{2}{*}{$\begin{array}{c}\text { Stratified } \\
\text { Weight }\end{array}$} & $12-25 \mathrm{~kg}$ & 30 & 13 & 8 & 9 & 60 & \multirow[t]{3}{*}{0.174} \\
\hline & $26-48 \mathrm{~kg}$ & 40 & 33 & 19 & 8 & 100 & \\
\hline \multicolumn{2}{|c|}{ Total } & 70 & 46 & 27 & 17 & 160 & \\
\hline
\end{tabular}


Table 4:

Severity of Pain (Facial Expressions) in Group (DS)

\begin{tabular}{|c|c|c|c|c|}
\hline Group & Time & Levels of Pain & Frequency & Percentage (\%) \\
\hline \multirow[t]{15}{*}{ DS } & \multirow[t]{5}{*}{ O Hour } & No Pain & 23 & 29.6 \\
\hline & & Mild & 33 & 40.7 \\
\hline & & Moderate & 15 & 18.5 \\
\hline & & Severe & 9 & 11.1 \\
\hline & & Total & 80 & 100.0 \\
\hline & \multirow[t]{5}{*}{2 Hours } & No Pain & 40 & 50.0 \\
\hline & & Mild & 18 & 23.1 \\
\hline & & Moderate & 10 & 11.5 \\
\hline & & Severe & 12 & 15.4 \\
\hline & & Total & 80 & 100.0 \\
\hline & \multirow[t]{5}{*}{4 Hours } & No Pain & 50 & 63.0 \\
\hline & & Mild & 15 & 18.5 \\
\hline & & Moderate & 9 & 11.1 \\
\hline & & Severe & 6 & 7.4 \\
\hline & & Total & 80 & 100.0 \\
\hline
\end{tabular}

Table 5:

Severity of Pain (Facial Expressions) in Group (DI)

\begin{tabular}{|c|c|c|c|c|}
\hline Group & Time & Levels of Pain & Frequency & Percentage (\%) \\
\hline \multirow[t]{15}{*}{ DI } & \multirow[t]{5}{*}{0 Hour } & No Pain & 18 & 23.1 \\
\hline & & Mild & 37 & 46.2 \\
\hline & & Moderate & 21 & 26.9 \\
\hline & & Severe & 4 & 3.8 \\
\hline & & Total & 80 & 100.0 \\
\hline & \multirow[t]{5}{*}{2 Hours } & No Pain & 34 & 42.3 \\
\hline & & Mild & 21 & 26.9 \\
\hline & & Moderate & 9 & 11.5 \\
\hline & & Severe & 16 & 19.2 \\
\hline & & Total & 80 & 100.0 \\
\hline & \multirow[t]{5}{*}{4 Hours } & No Pain & 43 & 53.6 \\
\hline & & Mild & 14 & 17.9 \\
\hline & & Moderate & 17 & 21.4 \\
\hline & & Severe & 6 & 7.1 \\
\hline & & Total & 28 & 100.0 \\
\hline
\end{tabular}

\section{Discussion:}

The results of our study reveal that there is almost no difference between the effectiveness of both suppository and intramuscular Diclofenac when given post operatively. But there is lower pain rating scale with suppository type of modality. Moreover suppository route is safer, less prone to injury, easy to administer and has longer duration of action.

Suppository route is also known to be as newer route to treat children in $21^{\text {st }}$ century by Vincent Jannin et al $\{10\}$. A comprehensive meta-analysis compares the rectal and oral routes for reducing fever. It was concluded by the equivalence of these two routes and it may change the recomendation of The American Academy of Pediatrics, whose recommendation was, so far, to refrain rectal administration to children $\{11\}$.Diclofenac is used as an analgesic in pre- and post-operative pain management and illustrates excellent effectiveness by suppository administration alone, or in combination with other drugs $\{12\}$. 
Several studies have explored the use of paracetamol and Diclofenac in pediatric patients. Concurrent administration of Diclofenac in children receiving patient-controlled analgesia (PCA) morphine has a very considerable morphine-sparing effect, as demonstrated by Morton and O'Brien, although they were unable to explain any extra additive outcome of paracetamol $\{13\}$.

Our study is concerned with postoperative use of Diclofenac via rectal and intramuscular route while most of the previous studies were concerned with preoperative administration of Diclofenac in children undergoing inguinal hernia. In a similar study by W Riad and A Moussa preoperative Diclofenac suppository in combination with paracetamol was used which shows that its use spared the post operative use of morphine $\{14\}$.

Sodium diclofenac is an non steroidal anti-inflammatory durgs) which shows analgesic affects in various conditions. A study suggests that sodium diclofenac presents the advantages that it could restrain prostaglandin biosynthesis by blocking the cyclo-oxygenase enzyme. By decreasing the production of prostaglandins, the feeling of pain may diminish in the peripheral nervous system; although a central anti-nociceptive effect has also been claimed for NSAIDs. Opioids are usually unable to remove the chemical mediators of pain and by using meperidine, the patients still have a vague feeling of pain. Furthermore, sodium diclofenac does not result in respiratory depression or any other meperidine side effects such as vomiting, nausea, respiratory depression, itching, decreased gastrointestinal (GI) motility, tachycardia and physical dependency and hemodynamic instability. Sodium diclofenac similar to other NSAIDS has some gastrointestinal effects and there is a speculative risk of postoperative hemorrhage as it causes prolonged bleeding time and decreases platelet aggregation $\{15\}$.

In a preliminary study of the two marketed formulations of Diclofenac, Intramuscular and suppository revealed that both preparations provided comparable analgesia but patients who received the suppository preparation were released earlier $\{16\}$. In another study which compares Intramuscular diclofenac with intravenous paracetamol, it can be concluded that IM diclofenac appears to be a superior post-operative analgesic compared to intravenous paracetamol, with no added advantage of their combination over Intramuscular diclofenac, in terms of rescue analgesic requirements, in patients undergoing lower abdominal gynecological surgery $\{17\}$.

Diclofenac suppository is a superior choice for post-operative analgesia in paediatric patients going through tonsillectomy in comparison to bupivacaine infiltration as there were considerable variation in pain score $(\mathrm{P}<0.05)$ after two hours onwards post operatively $\{18\}$.

In another study, which compared the postoperative analgesic effect of suppository diclofenac with caudal bupivacane suggested that suppository diclofenac although provides comparable analgesic effect postoperatively but immediate pain relief is difficult by the use of suppository diclofenac $\{19\}$.

A study on comparison of efficacy of NSAIDS when given through different routes was performed which revealed that fastest and most effective analgesia was provided by intravascular route of administration. But other than that there was no significant difference in analgesic effect. In the same study it was shown that most side effects were through intramuscular route and rectal route i.e. discomfort at the site of injection (intramuscular route) and diarrhea, rectal irritation and non-retention of suppositories (rectal route) $\{20\}$.

\section{Conclusion:}

From this study we conclude that there is no significant difference between the postoperative analgesic effect of either suppository or intramuscular diclofenac but suppository route has an advantage over intramuscular in that it is easier and safer, less prone to injury, easy to administer and has longer duration of action, especially preferable in pediatric patients.

Funding Source: NIL

Conflict of interest: There is no conflict of interest.

\section{References:}

1- Chang SJ, Chen JY, Hsu CK, Chuang FC, Yang SS. The incidence of inguinal hernia and associated risk factors of incarceration in pediatric inguinal hernia: a nation-wide longitudinal population-based study. Hernia. 2016.; 20 (4):559-63.

2- Kelly KB, Ponsky TA. Pediatric abdominal wall defects. Surgical Clinics of North America. 2013 ;93(5):1255-1267 
3- Komorowski AL, Moran Rodriguez J, Kazi R, Wysocki WM. Sliding Inguinal Hernias. Int J Surg 2012;10(4):206-208

4- Townsend CM, Beauchamp RD, Evers BM, Mattox KL. Textbook of surgery. Stomach, 19th edn. Elsevier, Philadelphia. 2012:1182-226.

5- Inaba T, et al. Chronic pain and discomfort after inguinal hernia repair. Surgery Today. 2012; 42(9):825-829.

6- Banik D, Hye MA, Akhtaruzzaman A, Aziz L, Yeasmeen S, Iqbal K. Effect of small dose intermittent IV pethidine in combination with diclofenac for post operative pain relief. Journal of the Bangladesh Society of Anaesthesiologists. 2014;22(2):40-47.

7- Barkhori A, Drodian MR, Norozi M, Hashemi Shadmehri M, Shabani M. A comparative study of the effect of diclofenac, indomethacin, naproxen, and acetaminophen rectal suppositories on post-cesarean pain. J Birjand Univ Med Sci. 2014; 20(4):338-45.

8- Crofford LJ. Use of NSAIDs in treating patients with arthritis. Arthritis research \& therapy. 2013; 15(3):S2.

9- Sede SS, Tanha FD, Valadan M, Modaressi Z. Comparison between Preoperative Rectal Diclofenac Plus Paracetamol and Diclofenac Alone for PostoperativePain of Hysterectomy. Journal of family \& reproductive health. 2014; 8(3):91.

10- Jannin V, Lemagnen G, Gueroult P, Larrouture D, Tuleu C. Rectal route in the 21 st century to treat children. Advanced drug delivery reviews. 2014; 73:34-49.

11- Prins SA, Van Dijk M, Van Leeuwen PI, Searle S, Anderson BJ, Tibboel D, Mathot RA. Pharmacokinetics and analgesic effects of intravenous propacetamol vs rectal paracetamol in children after major craniofacial surgery. Pediatric Anesthesia. 2008; 18(7):582-92.

12- Adarsh ES, Mane R, Sanikop CS, Sagar SM. Effect of pre-operative rectal diclofenac suppository on post-operative analgesic requirement in cleft palate repair: A randomised clinical trial. Indian journal of anaesthesia. 2012; 56(3):265.

13- Morton NS, O'Brien K. Analgesic efficacy of paracetamol and diclofenac in children receiving PCA morphine. Br J Anaesth 1999; 82(5):715-7.

14- Riad W, Moussa A. Pre-operative analgesia with rectal diclofenac and/or paracetamol in children undergoing inguinal hernia repair. Anaesth. 2007; 62(12):1241-5.

15- Alijanpour E, Jabbari A, Rabiea SM, Tabasi S. Suppository diclofenac instead of intravenous meperidine for postoperative management. Caspian J Intern Med. 2012; 3(3):506.

16- Pinto PL, Chen D, Clement Y, Simeon D. Analgesic effects of diclofenac suppository and injection after preoperative administration. Int J Clin Pharmacol Res. 1999; 19(2):47-51.

17- Pal A, Biswas J, Mukhopadhyay P, Sanyal P, Dasgupta S, Das S. Diclofenac is more effective for postoperative analgesia in patients undergoing lower abdominal gynecological surgeries: A comparative study. Anesth Essays Res. 2014; 8(2):192.

18- Solanki NS, Goswami M, Thaker N. Bupivacaine infiltration versus diclofenac suppository for posttonsillectomy pain relief in paediatric patients. Natil J Med Res. 2012; 2(1):5-7.

19- Moores M, Wandless J, Fell D. Paediatric postoperative analgesia A comparison of rectal diclofenac with caudal bupivacaine after inguinal herniotomy. Anaesth. 1990; 45(2):156-8.

20- Tramír DM, Williams J, Carroll D, Wiffen P, Moore R, McQuay H. Comparing analgesic efficacy of non-steroidal anti-inflammatory drugs given by different routes in acute and chronic pain: a qualitative systematic review. Acta Anaesthesiologica Scandinavica. 1998; 42(1):71-9. 